\title{
Intravitreal dexamethasone implant versus triamcinolone acetonide for macular oedema of central retinal vein occlusion: quantifying efficacy and safety
}

\author{
S. K. Mishra ${ }^{*}$, A. Gupta², S. Patyal ${ }^{3}$, S. Kumar ${ }^{3}$, K. Raji ${ }^{3}$, A. Singh ${ }^{3}$ and V. Sharma ${ }^{3}$
}

\begin{abstract}
Purpose: Among the retinal vascular diseases, burden of retinal vein occlusion is most common immediately after diabetic retinopathy. Intravitreal corticosteroids are gaining popularity in managing macular edema (ME) of RVO. Our study compares efficacy and safety of intravitreal triamcinolone (IVTA) and dexamethasone implant (IVD) over 6 months.
\end{abstract}

Methods: This comparative, prospective, randomized study on 40 patients of non-ischemic central RVO with significant ME (> $330 \mu \mathrm{m})$ of < 3 months duration. Study was done at Army Research Hospital between Sep-2012 and May2014 in accordance to Helsinki Declaration. IVD group $(n=20)$ received Ozurdex ${ }^{\circledR}$ while IVTA group $(n=20)$ received triamcinolone-acetonide (4 mg/0.1 ml), followed up at day-1 and weeks 4, 8, 12, 24.

Results: At 6 months, mean improvement in best corrected visual acuity and retinal thickness (CMT) in the IVD group was 0.43 logmar and $323 \mu \mathrm{m}$ and in IVTA group was 0.49 logmar and $322 \mu \mathrm{m}$ respectively. Proportion of patients achieving $\geq 15$ letters was about 40\% in both groups. IOP rise was significantly higher in IVTA group at 12 and 24 weeks. In IVTA group $\geq 10 \mathrm{mmHg}$ IOP rise was seen in $60 \%$ of patients, $41.6 \%$ among them had $>35 \mathrm{mmHg}$ and $66 \%$ needed combination treatment and failed to reach baseline line IOP at 6 months. In IVD group, 5 pts had IOP rise with all being $<26 \mathrm{mmHg}$ and were easily managed with single agent with IOP reaching baseline by 6th month in all pts. Relative risk of IOP rise with IVTA is 2.4 times higher compared to IVD. Cataract progression and cataract surgeries were required at significantly higher rates in IVTA group. In IVTA group, cataract progression was seen in 35\% patients, with $71.5 \%$ requiring cataract surgery at 6 months. IVD group, 10\% patients had cataract progression while none required surgery at 6 months. Relative risk of cataract progression with IVTA is 3.5 times higher compared to IVD.

Conclusion: Intravitreal steroids are effective in managing macular edema of retinal vein occlusion, while newer formulation of sustained release dexamethasone implant is significantly safer than IVTA.

Keywords: Central retinal vein occlusion, CRVO, Non ischaemic CRVO, IVTA, Triamcinalone acetonide, Ozurdex, Dexamethasone implant

\section{Introduction and purpose}

Among the retinal vascular diseases, burden of retinal vein occlusion is most common immediately after

\footnotetext{
*Correspondence: sanjusonu_2000@yahoo.com

${ }^{1}$ Department of Ophthalmology Command hospital, Lucknow cantt 226002, India

Full list of author information is available at the end of the article
}

diabetic retinopathy [1]. Central RVO (CRVO) impedes blood supply leading to retinal ischaemia, edema and significant ocular morbidity. Incidence is common in persons over 65 years, while affecting either sexes equally [2-4]. Prevalence of CRVO is reported at $0.1-0.4 \%[2,5]$, with worsening of vision related quality of life [6].

Intravitreal corticosteroids are gaining popularity in managing ME of RVO as its effects span over controlling 
and limiting angiogenesis, re-establishing retinal fluid homeostasis and reducing edema, additionally having anti-apoptotic and anti-proliferative effects. Advantages of intravitreal delivery include localised/targeted action in the retina with additional higher concentration of the drug with prolonged action. Commonly used intravitreal steroids are triamcinolone-acetonide and $0.7 \mathrm{mg}$ dexamethasone implant. Earlier studies have established both steroids in reducing macular edema with visual acuity improvement in patients of CRVO $[7,8]$.

Our study aims at comparative evaluation of intravitreal triamcinolone (IVTA) and dexamethasone implant (IVD) over 6 months.

\section{Methods}

Study design is prospective, comparative, randomized study, carried out at Army Hospital Research and Referral ophthalmology clinic between Sep-2012 and May-2014. The study is conducted in accordance with Declaration of Helsinki and approved by Institutional Research Board. Signed informed consents were obtained from all patients before enrolling into study. Forty patients of non-ischemic CRVO with significant $\mathrm{ME}(>330 \mu \mathrm{m})$ of $<3$ months duration were included. Clinical diagnosis was confirmed by FFA and OCT (Spectralis, Cirrus) with significant cystoid ME (CME) as defined by CRVO Study Group [9]. The exclusion criteria's were existence of other retinal vascular diseases (diabetic retinopathy, age related degeneration), glaucoma, previous treatments for CRVO (intravitreals or laser-photocoagulation), iris neovascularization and $>10$ disc retinal ischemia in FFA.

This prospective study is designed to evaluate the efficacy and safety of intravitreal triamcinolone and dexamethasone implant over a study period of 6 months. Intravitreal desamethasone group [IVD group $(n=20)$ ] received $0.7 \mathrm{mg}$ dexamethasone implant $\left(\right.$ Ozurdex $^{\circledR}$, Allergan) while intravitreal triamcinolone acetonide [IVTA group $(\mathrm{n}=20)]$ received $4 \mathrm{mg} / 0.1 \mathrm{ml}$ triamcinolone-acetonide (Kenacort ${ }^{\circledR}$, BMS). Study starts from the day of the injection and were followed up for a minimum of 6 months. Follow up evaluations were done on day 1 and week 4, followed by monthly evaluations for a minimum duration of 6 months. Reinjections of intravitreals were allowed in cases of recurrent edema and warranting treatment as judged by investigator. Recurrence of ME was defined as a decrease in VA $\leq 2$ lines or increase in intraretinal or subretinal fluid, with $\mathrm{ME} \geq 320 \mu \mathrm{m}$. Evaluations at baseline and follow-up included best corrected visual acuity (BCVA; Snellen chart at $6 \mathrm{~m}$ ), slit-lamp examination of anterior segment, intraocular pressure (IOP; Goldmann Tonometer), indirect ophthalmoscopy, FFA and OCT. The primary endpoints of the study were BCVA, CMT on OCT, IOP, and cataract progression.

Statistical analysis was done using Stata90 (College Station, USA). Data is presented as median (min-max) or number (\%) as appropriate. Continuous baseline characters were compared between groups using WilcoxonRanksum test and categorical baseline characteristics were compared using Fisher's exact test. The outcomes variable such as BCVA, IOP, CMT were compared between groups using Wilcoxon Ranksum test and within group using Wilcoxon Signed Ranksum test as sample size is small. Statistical significance was defined as value $<0.05$. VA is converted to logmar for statistical analysis.

\section{Results}

Of the 40 patients, 20 (11 men, 9 women) received IVTA and 20 (12 men, 8 women) received IVD for ME secondary to CRVO. The sex distribution was similar between groups $(\mathrm{P}=0.502)$, as was the mean patient age $(58.6 \pm 10.41$ vs. $57.9 \pm 8.77$ years; $\mathrm{P}=0.342)$. The mean follow-up time is 6 months in both groups. Mean baseline measurements in IVD versus IVTA group are BCVA (logmar) $(1.06 \pm 0.13$ vs. $0.99 \pm 0.15)$, CMT $(551 \pm 17.16$ vs. $547.5 \pm 13.79 \mu \mathrm{m})$ and IOP $(16.7 \pm 1.16$ vs. $16.1 \pm 2.60 \mathrm{mmHg}$ ) respectively, and were not statistically significant (Table 1). Arterial hypertension was diagnosed in ten subjects (IVD group-4 pts; IVTA group-6 pts). Seven patients had hyperlipidemia (IVD group-3 pts; IVTA group-4 pts). Eight patients were cigarette smokers in IVD group and nine smokers in IVTA group. Two subjects in IVD group required 2 IVD injections during study period. Four subjects in the IVTA group required 2 injections of IVTA during study period.

The mean BCVA improved by 0.43 logmar $(\mathrm{P}<0.001)$ in IVD group and by $0.49 \operatorname{logmar}(\mathrm{P}<0.001)$ in IVTA group at study end (Table 2). However, visual acuity gains between groups were not statistically significant (Table 3). CMT improved by $314 \mu \mathrm{m}$ in IVD group, while in IVTA group CMT improved by $314.9 \mu \mathrm{m}$ by 6 months after intravitreal injections. While within groups CMT improvements were statistically significant, between groups the improvement was not statistically valid $(\mathrm{P}=0.4244)$ (Tables 2,4$)$.

At 6 months, rise in IOP was statistically significant only in the IVTA group (Table 2). IOP lowering medication was initiated in 12 eyes $(60 \%)$ in the IVTA group and in 5 eyes $(25 \%)$ in IVD group in 6 months. All the 5 eyes in the IVD group had IOP of $<26 \mathrm{mmHg}$ and was readily controlled by single antiglaucoma medication and reached baseline by 6 months. Peak IOP was recorded at second month of follow up. In IVTA group IOP lowering medication was initiated in 12 eyes (60\%). 5 eyes (41.6\%) had IOP of more than $35 \mathrm{mmHg}$. Eight eyes (66.6\%) needed combination eye drops and did not normalise by 
Table 1 Baseline parameters in patients with CRVO

\begin{tabular}{lll}
\hline & Dexamethasone $(\mathbf{n}=\mathbf{2 0})$ & Triamcinolone acetonide $(\mathbf{n}=\mathbf{2 0})$ \\
\hline Sex $(M / F)$ & $12 / 8$ & $9 / 11$ \\
Mean age (years \pm SD) & $58.6 \pm 10.41$ & $57.9 \pm 8.77$ \\
Smoker $(n)$ & 8 & 9 \\
Hypertension (n) & 4 & 6 \\
Hyperlipidemia (n) & 3 & 4 \\
Follow up (months $\pm S D)$ & 6 & 6 \\
BCVA (logMAR \pm SD) & $1.06 \pm 0.13$ & $0.99 \pm 0.15$ \\
CMT $(\mu m \pm S D)$ & $551 \pm 17.16$ & $547.5 \pm 13.79$ \\
IOP $(m m H g \pm S D)$ & $16.7 \pm 1.16$ & $16.1 \pm 2.60$ \\
\hline
\end{tabular}

$B C V A$ best-corrected visual acuity, $C M T$ central macular thickness, IOP intraocular pressure, NS not significant

Table 2 Comparison of baseline and end-of-follow-up parameters in patients with central retinal vein occlusion

\begin{tabular}{|c|c|c|c|c|c|c|}
\hline & \multicolumn{3}{|c|}{ Dexamethasone $(n=20)$} & \multicolumn{3}{|c|}{ Triamcinolone $(n=20)$} \\
\hline & Baseline & After & $\mathbf{P}$ & Baseline & After & $\mathbf{P}$ \\
\hline$B C V A(\log M A R \pm S D)$ & $1.06 \pm 0.13$ & $0.637 \pm 0.54$ & 0.0179 & $0.99 \pm 0.15$ & $0.508 \pm 0.45$ & 0.0142 \\
\hline CMT $(\mu \mathrm{m})$ & $551 \pm 17.16$ & $237 \pm 20.71$ & 0.0050 & $547.5 \pm 13.79$ & $232.6 \pm 18.54$ & 0.0050 \\
\hline IOP $(\mathrm{mmHg})$ & $16.7 \pm 1.16$ & $17 \pm 1.94$ & 0.7083 & $16.1 \pm 2.60$ & $22.2 \pm 4.93$ & 0.0076 \\
\hline
\end{tabular}

BCVA best-corrected visual acuity, CMT central macular thickness, IOP intraocular pressure, NS not significant

Table 3 Comparison of logMAR BCVA between Ozurdex and triamcinolone at each follow up visit

\begin{tabular}{lllll}
\hline & $\begin{array}{l}\text { Ozu }(\mathrm{n}=20) \text { logmar } \\
\text { BCVA-median }\end{array}$ & Versus baseline; $P$ value & $\begin{array}{l}\text { Tri }(\mathrm{n}=20) \text { logmar BCVA- } \\
\text { median }\end{array}$ & $\begin{array}{l}\text { Versus baseline; } P \text { value } \\
\text { sus Tri } P \\
\text { value }\end{array}$ \\
\hline Baseline & 1.079 & - & 1.0395 & - \\
4 weeks & 0.778 & $0.107^{*}$ & 0.778 & $0.0107^{*}$ \\
8 weeks & 0.602 & $0.0352^{*}$ & 0.602 & $0.0246^{*}$ \\
12 weeks & 0.477 & $0.0208^{*}$ & 0.477 & 0.9071 \\
24 weeks & 0.477 & $0.0179^{*}$ & 0.389 & $0.0188^{*}$ \\
\hline
\end{tabular}

*Statistically significant

Table 4 Comparison of CMT between Ozurdex and triamcinolone at each follow up visit

\begin{tabular}{lllll}
\hline & $\begin{array}{l}\text { Ozu }(\mathrm{n}=\mathbf{2 0}) \text { mean } \\
\text { CMT- } \boldsymbol{\mu m}\end{array}$ & Versus Baseline; P value & $\begin{array}{l}\text { Tri }(\mathbf{n}=\mathbf{2 0}) \text { mean } \\
\text { CMT- } \boldsymbol{\mu m}\end{array}$ & $\begin{array}{l}\text { Versus baseline; P value } \\
\text { Ozu versus Tri } \\
\text { P value }\end{array}$ \\
\hline Baseline & 555 & - & 552 & - \\
4 weeks & 450 & $0.0050^{*}$ & 402 & 0.5362 \\
8 weeks & 350 & $0.0050^{*}$ & 330 & $0.050^{*}$ \\
12 weeks & 270 & $0.0049^{*}$ & 240 & $0.0050^{*}$ \\
24 weeks & 232 & $0.0050^{*}$ & 230 & $0.0050^{*}$ \\
\hline
\end{tabular}

*Statistically significant

6 months of study. The statistical analysis of IOP comparison between dexamethasone and triamcinolone was significant at 12 and 24 weeks with triamcinolone group showing increased IOP (Table 5). Within the Ozurdex group the change in IOP from baseline was statistically significant up till 12 weeks but by the end of 24 weeks this change became statistically insignificant but in the triamcinolone group this was statistically significant by the end of 6 month period (Table 5). Relative risk of IOP rise with IVTA is 2.4 times higher compared to IVD. 
Table 5 Comparison of IOP between Ozurdex and triamcinolone at each follow up visit

\begin{tabular}{llllll}
\hline & $\begin{array}{l}\text { Ozu }(\mathbf{n}=20) \\
(\mathbf{m m H g})\end{array}$ & & median IOP & $\begin{array}{c}\text { Versus baseline; P value } \\
\text { Tri }(\mathbf{n = 2 0}) \text { median IOP } \\
(\mathbf{m m H g})\end{array}$ & $\begin{array}{l}\text { Versus baseline; P value } \\
\text { Ozu ver- } \\
\text { sus Tri P } \\
\text { value }\end{array}$ \\
\hline Baseline & 17 & - & 15 & - & 0.4144 \\
4 weeks & 18 & $0.0113^{*}$ & 23 & $0.0 .0076^{*}$ & 0.2532 \\
8 weeks & 19 & $0.0036^{*}$ & 27 & $0.0058^{*}$ & 0.1918 \\
12 weeks & 18 & $0.0048^{*}$ & 26 & $0.0058^{*}$ & $0.0354^{*}$ \\
24 weeks & 16 & 0.7083 & 25 & $0.0076^{*}$ & $0.0110^{*}$ \\
\hline
\end{tabular}

*Statistically significant

Of the phakic eyes at baseline, 7 eyes (35\%) in the IVTA group either had new onset lens opacity or progression of an existing opacity through month 6 as compared to 2 in the IVD group. In the IVTA group, 5 eyes (71.5\%) of the 7 eyes with significant cataract progression, required cataract surgery at end of follow up period. Relative risk of cataract progression with IVTA is 3.5 times higher compared to IVD. No reports of infectious endophthalmitis were noted in either of the groups during the study period. Minor ocular adverse events related to injection procedure such as vitreous floaters and conjunctival haemorrhage occurred in similar number of eyes in both groups. Representative Fundus, FFA and OCT images before and after intervention with IVD is as seen in Figs. 1, 2 and 3 respectively and those after IVTA are as seen in Figs. 4, 5, and 6 respectively.

\section{Discussion}

Studies related to TCA done by Cekic et al. [10] reported average gain in VA in patients treated with TCA is 1.3 Snellen lines (range -3 to 7 ) over the course of 10 months. Out of 24,10 eyes gained $\geq 2$ lines of VA, 3 eyes improved 1-line, 7 eyes remained the same, and 4 eyes worsened. There was no correlation between improvement in foveal thickness and corresponding visual gain. The SCORE [8] study group concluded that out of 271 patients, $27 \%$ participants in 4-mg TCA group achieved $\geq 15$-letters improvement from the baseline. Jonas et al. [11] reported an improvement in VA by atleast 2 Snellen lines and 3 Snellen lines, respectively, in 8 (62\%) eyes and 5 (38\%) eyes treated with triamcinolone. VA measurements at 1 month $(\mathrm{P}=0.038)$ and 3 months $(\mathrm{P}=0.046)$ after the injection were significantly higher than the baseline values. Increase in VA was higher in the non-ischemic subgroup than the ischemic subgroup. Patel [12] et al. reported VA improvement $\geq 2$ Snellen lines in eight (62\%) eyes with mean VA improvement of 0.46 logmar with TCA intervention. The studies related to dexamethasone done by GENEVA [7] study group reported $22 \%$ participants in $0.7 \mathrm{mg}$ dexamethasone group achieved $\geq 15$-letters improvement from baseline. Joshi et al. [13] reported mean change in VA at 12 months with Ozurdex compared to baseline for CRVO was $11.5 \pm 11.0$ EDTRS letters, $30 \%$ of eyes gained $\geq 15$
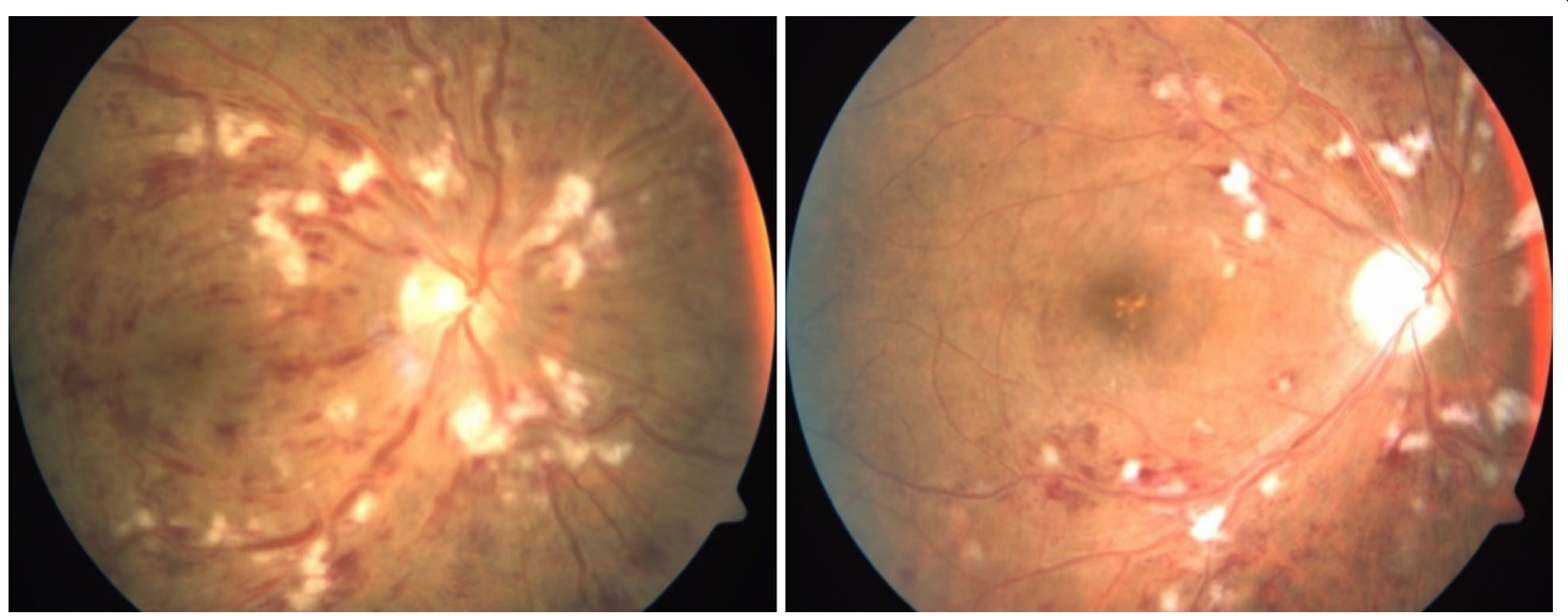

Fig. 1 Fundus photo pre and post Inj Ozurdex 

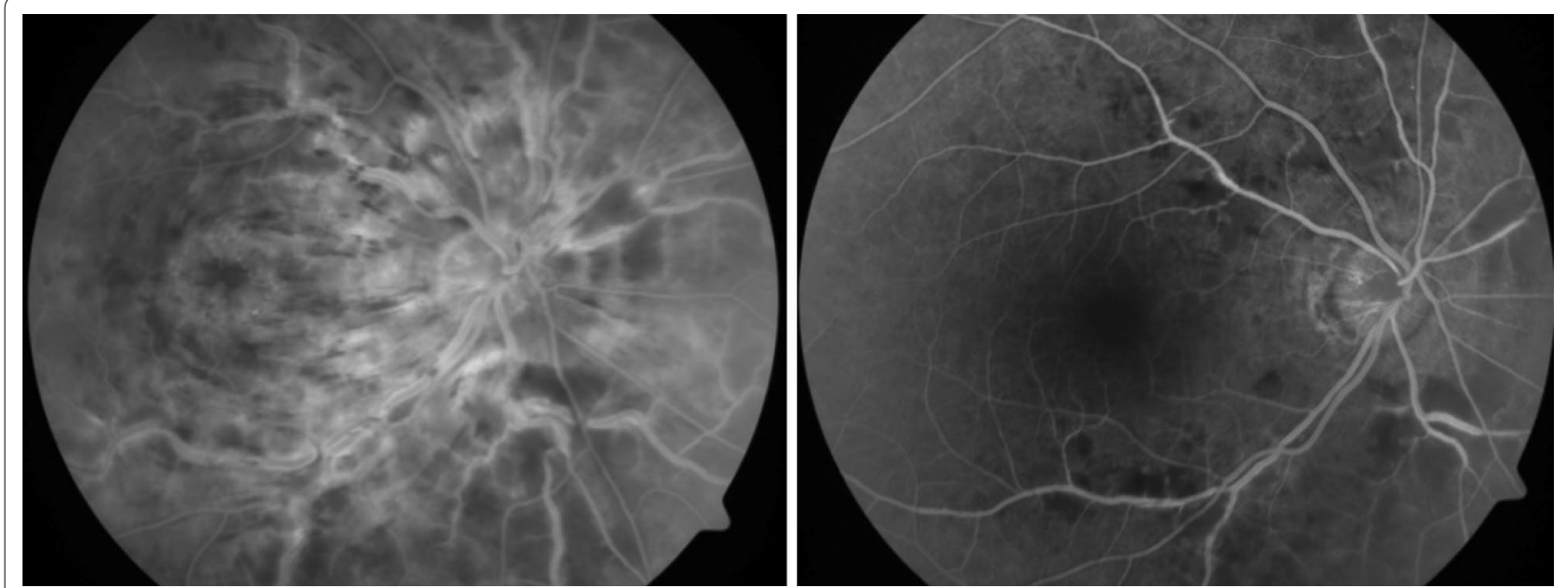

Fig. 2 FFA pre and post Inj Ozurdex showing resolving macular oedema
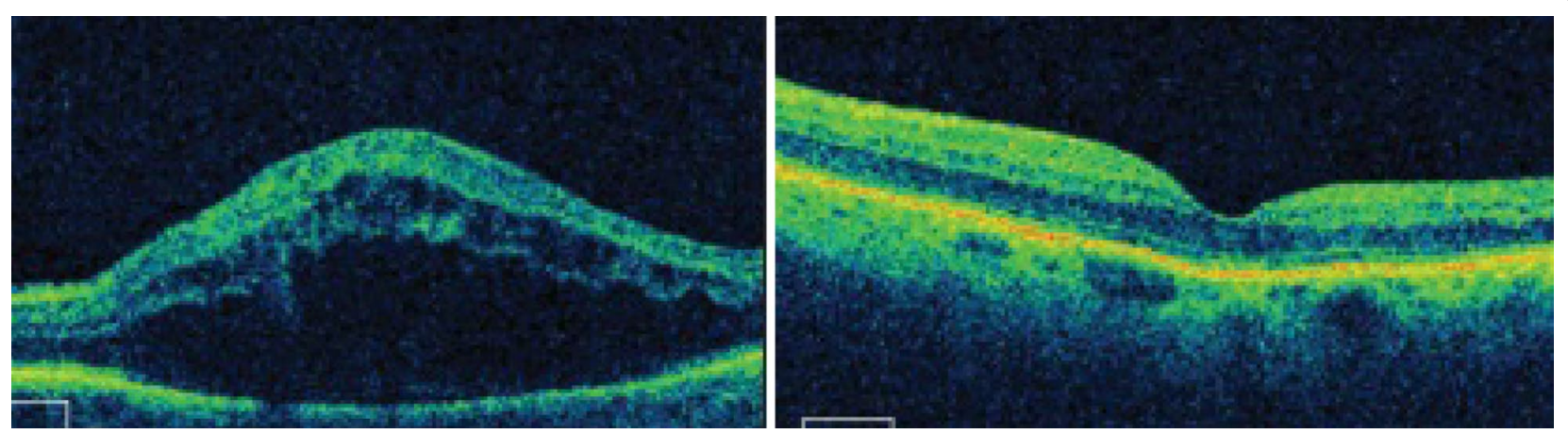

Fig. 3 OCT macula pre and post Inj Ozurdex
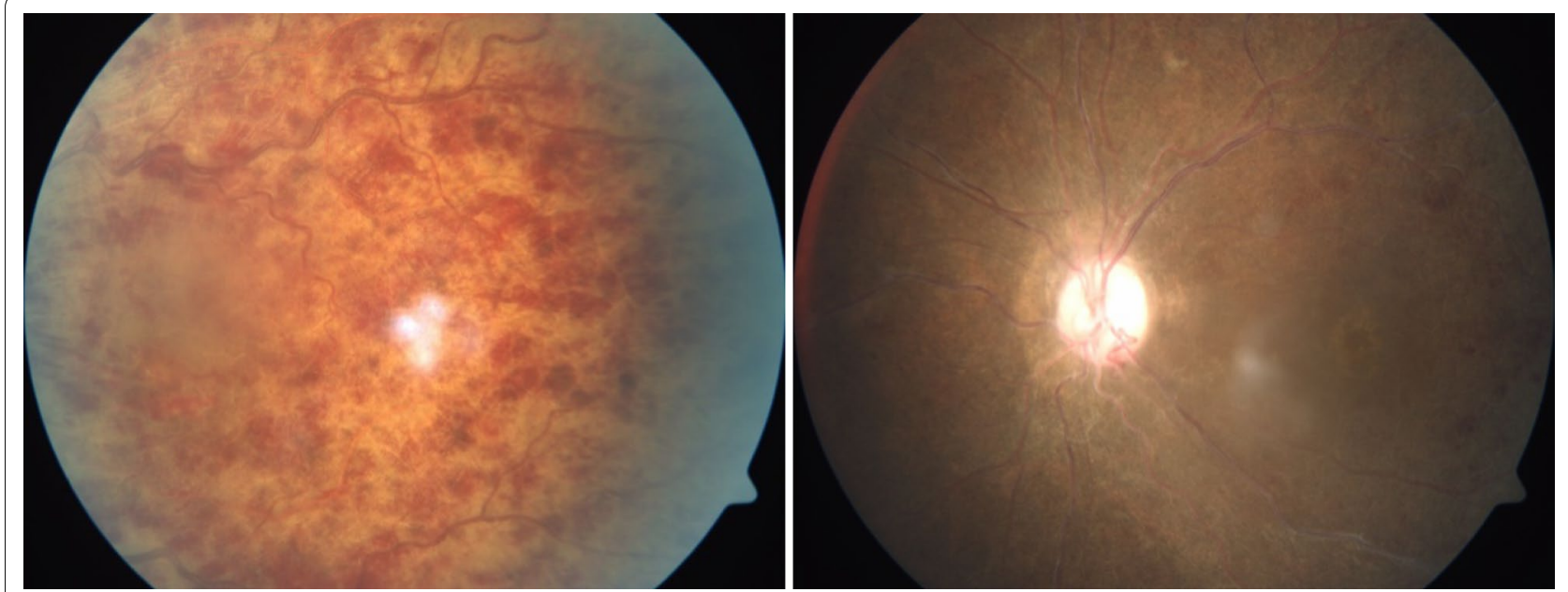

Fig. 4 Fundus photo pre and post Inj triamcinolone 

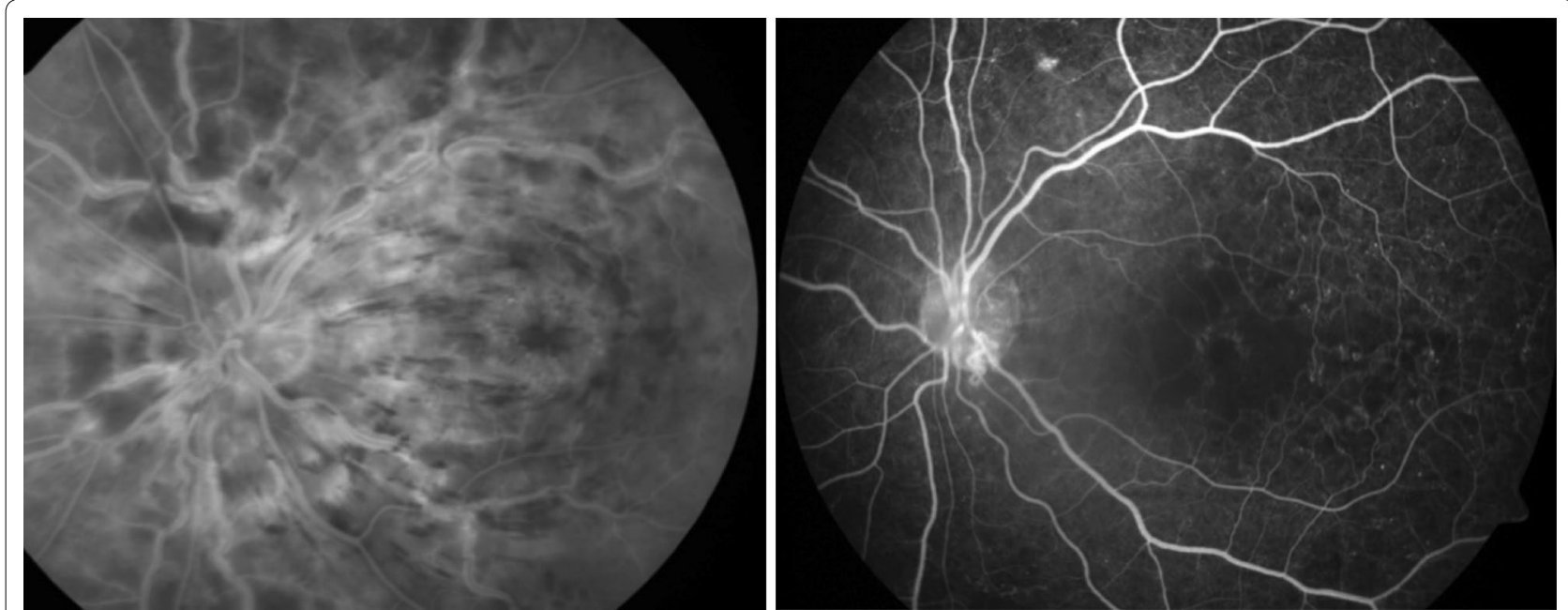

Fig. 5 FFA pre and post Inj triamcinolone showing resolving macular oedema with capillary non perfusion areas and enlarged and distorted foveal avasular zone
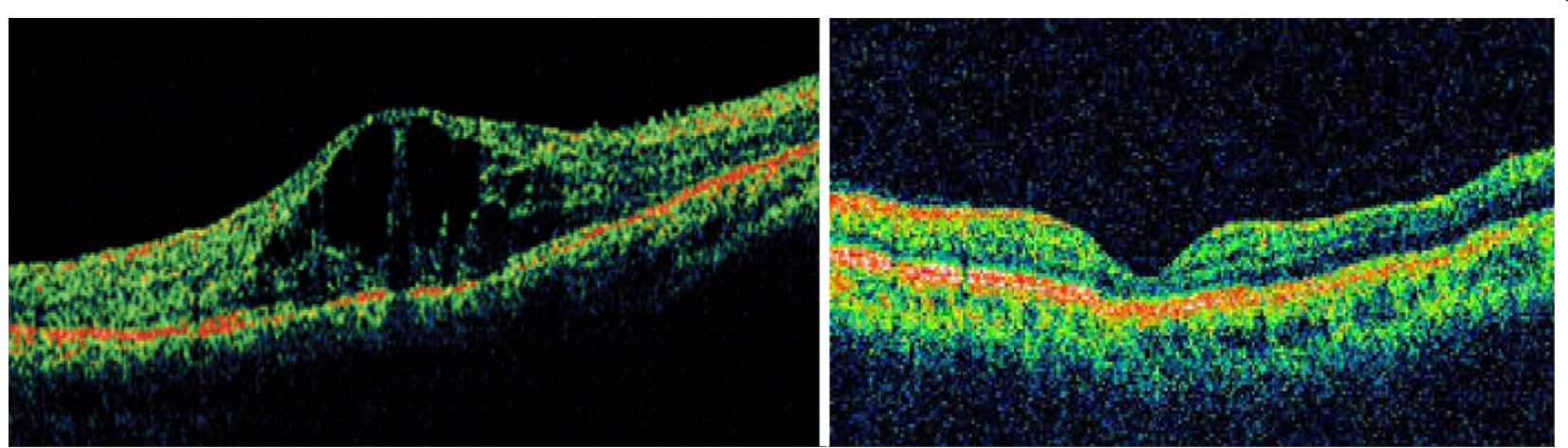

Fig. 6 OCT macula pre and post Inj triamcinolone

letters. Visual outcomes are similar to those previously seen with TCA in the SCORE study [8].

Our study shows that, likelihood of a gain in VA letter score of $\geq 15$ at 6 months is similar in IVTA and IVD groups. At all-time points through 6 months, mean VA improvements are comparable between IVD and IVTA groups. At 6 months, mean improvement in BCVA was 0.43 and 0.49 logmar in IVD and IVTA groups, respectively and was not statistically significant between groups (Table 3). Within both groups there was significant improvement in VA at each follow up visit. In our study $8 / 20$ subjects $(40 \%)$ in both groups achieved $\geq 15$ letters improvement from baseline till 24 weeks. This is in concurrence with other studies which have reported that steroids improve VA in patients of ME due to CRVO.

There was no statistical difference between groups in CMT at 6 months (Table 4). In both treatment arms $18 / 20$ (90\%) subjects achieved CMT of $\leq 250$ microns at the end of 6 months period. In the GENEVA [7] study for dexamethasone implant $40 \%$ subjects achieved CMT $<250$ microns at 6 months, while the SCORE study group reported $38 \%$ subjects with CMT of $\leq 250$ microns at 6 months. Cekic $\mathrm{O}$ et al. [10] reported that in TCA treated patients the mean CMT decreased to $55 \%$ of preinjection values $[(\mathrm{n}=23) 635$ vs. $352 \mu \mathrm{m}$, respectively; $\mathrm{P}<0.001$ ]. Ip et al. [14] reported that mean baseline CMT before TCA injection was $590 \mu \mathrm{m}$ and improved to $281 \mu \mathrm{m}$ at 6 -months in 13 patients. Patel et al. [12] reported that CMT decreased significantly by $259 \mu \mathrm{m}$ (45\% improvement) at best after treatment (SD $94 \mu \mathrm{m} ; P=0.000017$ ), with five eyes achieving a thickness $\leq 250 \mu \mathrm{m}$ in 13 patients injected with triamcinolone.

In our study at 6 months, mean improvement in CMT was 323 and $322 \mu \mathrm{m}$ in IVD and IVTA groups, respectively. In both treatment arms $18 / 20$ (90\%) subjects achieved CMT of $\leq 250 \mu \mathrm{m}$ at 6 months and was 
statistically similar between groups. Comparatively greater proportion of patients achieved reduction in CMT. This may be attributed to selective inclusion of patients with shorter duration of ME of $<3$ months yielding better prognosis than patients with longer duration ME. Within groups there was statistically significant reduction of CMT at each follow-up in both treatment arms (Table 5).

In regards to safety outcome for dexamethasoneimplant, GENEVA [7] study reported that $15 \%$ study eyes showed IOP elevation of at-least $25 \mathrm{mmHg}$ peaking at day 60 and normalising by day 180 . While triamcinolone in SCORE [8] study reported 35\% of study eyes with IOP rise and 8 subjects having IOP $>35 \mathrm{mmHg}$. Cekic et al. [10] reported that $9 / 18$ patients without a history of glaucoma developed ocular hypertension and required glaucoma medication during post-TCA injection follow-up. Trabeculectomy was performed on 2 eyes with glaucoma. Ip et al. [14] reported that out of 13 patients on TCA, 1 patient experienced IOP rise that was controlled with 2 aqueous suppressants. Jonas et al. [11] reported that in the TCA group, IOP increased significantly $(\mathrm{P}=0.018)$ from $14.4 \pm 3.9 \mathrm{mmHg}$ to a mean maximal value of $21.6 \pm 9.2 \mathrm{mmHg}$ (range 10-44 $\mathrm{mmHg}$ ) and decreased $(\mathrm{P}=0.012)$ towards the end of 10 month follow-up to $15.3 \pm 5.1 \mathrm{mmHg}$ (range $10-21 \mathrm{mmHg}$ ). Patel [12] reported an IOP rise in 8/13 (62\%) eyes during followup. Maximum IOP $<30 \mathrm{mmHg}$ was seen in 4 eyes, while $<40 \mathrm{mmHg}$ was seen in 2 eyes and both these patients were adequately managed with topical medications. In total, 5 eyes $(38 \%)$ required IOP lowering medication at the end of follow-up.

In our study, IVTA group required more intervention in terms of IOP lowering medications compared to IVD group. Twelve cases $(60 \%)$ in IVTA group showed elevated IOP, of which 8 (66.6\%) were managed with combination eye drops and difference was statistically significant from baseline at 6 months (Table 3). However, in IVD group IOP rise was manageable with single antiglaucoma medication and returned to baseline by 6 months (Table 3).

Endophthalmitis was not reported in either of these. Seven phakic eyes (35\%) in IVTA group either had new onset lens opacity or progression of an existing opacity through month 6 as compared to $2(10 \%)$ in the IVD group. In IVTA group, 5 of 7 (71.4\%) with significant cataract progression required cataract surgery at 6 months while none required cataract surgery in IVD group.

Thus, our study demonstrates that dexamethasone $0.7 \mathrm{mg}$ sustained release implant and triamcinolone-acetonide are effective in restoring vision in patients of early CRVO, with a high proportion (40\%) gaining $\geq 3$ lines. In terms of safety, drug induced IOP rise $35 \%$ lesser with dexamethasone implant compared to IVTA. With IVTA there is probability of $42 \%$ patients experiencing IOP rise $>35 \mathrm{mmHg}$ and about $67 \%$ requiring combination antiglaucoma medications and fail to normalise at 6 months. Cataract progression and propensity for cataract surgery is 25 and $100 \%$ lesser with dexamethasone implant at 6 months' therapy. Our sample size is small, with longest follow up of 18 months, larger study with longer follow up is needed to establish these findings.

\section{Conclusion}

Intravitreal steroids are effective in managing macular edema of retinal vein occlusion, while newer formulation of sustained release dexamethasone implant is significantly safer than IVTA.

\section{Authors' contributions}

SKM has mentored and guided this study, from conceptualising, recruitment to manuscript writing. AG contributions include study conduct, patient follow-ups, preparing data master sheet and data analysis. SP, SK, KR and AS have contributed to recruitment, patient follow ups and in study conduct. All authors have read and approved the final manuscript.

\section{Author details}

${ }^{1}$ Department of Ophthalmology Command hospital, Lucknow cantt 226002, India. ${ }^{2}$ Department of Ophthalmology, Army Hospital Research and Referral, Delhi Cantt, New Delhi 110010, India. ${ }^{3}$ Army Hospital Research and Referral, Delhi Cantt, New Delhi 110010, India.

\section{Ethics approval and consent to participate}

The study is conducted in accordance with Declaration of Helsinki and approved by Institutional Research Board. Informed consent was obtained from all patients before enrolling into study. This study is registered at Delhi university with the registration no: MS-OPHTHALMOLOGY: 2012-2015/2/22.

\section{Competing interests}

The authors declare that they have no competing interests. This paper has never been submitted to any journal nor published in any form of media before.

\section{Publisher's Note}

Springer Nature remains neutral with regard to jurisdictional claims in published maps and institutional affiliations.

Received: 22 December 2017 Accepted: 9 March 2018

Published online: 26 March 2018

\section{References}

1. Orth DH, Patz A. Retinal branch vein occlusion. Surv Ophthalmol. 1978;22:357.

2. Hayreh SS, Zimmerman MB, Podhajsky P. Incidence of various types of retinal vein occlusion and their recurrence and demographic characteristics. Am J Ophthalmol. 1994;117:429-41.

3. Mitchell P, Smith W, Chang A. Prevalence and associations of retinal vein occlusion in Australia. The Blue Mountains Eye Study. Arch Ophthalmol. 1996;114:1243-7.

4. Group TCVOS. Baseline and early natural history report: the Central Vein Occlusion Study. Arch Ophthalmol. 1993;111:1087-95.

5. Klein R, Klein BE, Moss SE, Meuer SM. The epidemiology of retinal vein occlusion: the Beaver Dam Eye Study. Trans Am Ophthalmol Soc. 2000;98:133-41. 
6. Deramo VA, Cox TA, Syed AB, et al. Vision-related quality of life in people with central retinal vein occlusion using the 25 -item National Eye Institute Visual Function Questionnaire. Arch Ophthalmol. 2003;121:1297-302.

7. Haller JA, Bandello F, Belfort R Jr, Blumenkranz MS, Gillies M, Heier J, Loewenstein A, Yoon YH, Jacques ML, Jiao J, et al. Randomized, shamcontrolled trial of dexamethasone intravitreal implant in patients with macular edema due to retinal vein occlusion. Ophthalmology. 2010;14(6):1134-46.

8. The SCORE Study Research Group. A randomized trial comparing the efficacy and safety of intravitreal triamcinolone with observation to treat vision loss associated with macular edema secondary to central retinal vein occlusion. The standard care vs corticosteroid for retinal vein occlusion (SCORE) study report 5. Arch Ophthalmol. 2009;127:1101-14.

9. Central Vein Occlusion Study Group. Natural history and clinical management of central retinal vein occlusion. Arch Ophthalmol. 1997:115:486-91.
10. Cekic O, Chang S, Tseng JJ, et al. Intravitreal triamcinolone treatment for macular edema associated with central retinal vein occlusion and hemiretinal vein occlusion. Retina. 2005:25:846-50.

11. Jonas JB, Akkoyun I, Kamppeter B, et al. Intravitreal triamcinolone acetonide for treatment of central retinal vein occlusion. Eur J Ophthalmol. 2005;15:751-8.

12. Patel PJ, et al. Intravitreal triamcinolone acetonide for macular oedema owing to central retinal vein occlusion. Retina. 2001;21:408-15.

13. Joshi L et al. Dexamethasone implants in retinal vein occlusion: 12-month clinical effectiveness using repeat injections as-needed. Br J Ophthalmol. 2013;97(8):1040-4.

14. Ip MS, Gottlieb JL, Kahana A, et al. Intravitreal triamcinolone for the treatment of macular edema associated with central retinal vein occlusion. Arch Ophthalmol. 2004;122:1131-6.

\section{Submit your next manuscript to BioMed Central and we will help you at every step:}

- We accept pre-submission inquiries

- Our selector tool helps you to find the most relevant journal

- We provide round the clock customer support

- Convenient online submission

- Thorough peer review

- Inclusion in PubMed and all major indexing services

- Maximum visibility for your research

Submit your manuscript at www.biomedcentral.com/submit 